\title{
Demographic, Social-Emotional and Educational Aspects of Specific and Generalized Social Anxiety Subtypes Among Palestinian Arab Minority Student Teachers in Israel
}

\author{
Ihab Zubeidat ${ }^{1}$, Waleed Dallasheh ${ }^{1}$ \& Abed Alrahman Khalil ${ }^{1}$ \\ ${ }^{1}$ Sakhnin College Academic College for Teacher Education, Israel \\ Correspondence: Ihab Zubeidat, Sakhnin College Academic College for Teacher Education, Israel.
}

Received: January 31, 2018

doi:10.11114/ijsss.v6i4.3096

\author{
Accepted: March 1, 2018 \\ Available online: March 12, 2018 \\ URL: https://doi.org/10.11114/ijsss.v6i4.3096
}

\begin{abstract}
The current study is aimed to assess the differences between Palestinian Arab minority student teachers in Israel with specific and generalized social anxiety from various demographic, social-emotional and educational aspects. For this purpose, 543 Palestinian Arab minority student teachers in Israel from Sakhnin College responded to the research tools which measure these aspects and they were divided into three categories (no social anxiety, specific social anxiety, and generalized social anxiety). The findings indicated that the average age of the student teachers with generalized social anxiety was higher than the average age of those with specific social anxiety, while no differences were found between the two categories in certain demographic variables. The study found that average social anxiety, social fear and social avoidance levels were higher among student teachers with generalized social anxiety than among those with specific social anxiety. In addition, there is a statistically significant correlation between levels of social anxiety and levels of depression and motivation for learning, while there are no statistically significant links between levels of social anxiety and levels of self-esteem and perceived social and family support. A regression analysis reveals that the specific social anxiety levels of Palestinian Arab minority student teachers in Israel can be explained by the level of their perceived social and family support and their ages, whereas the levels of their generalized social anxiety can be explained by their depression levels and ages. The practical pedagogical implications suggest that both social anxiety student teachers groups should be exposed to educational- interventional programs in order to be integrated into the educational system.
\end{abstract}

Keywords: social anxiety, Palestinian Arab minority in Israel, learning motivation, self-esteem, student teachers

\section{Introduction}

The theoretical background begins with a description of the difficulties and stressors experienced by the Palestinian Arab minority student teachers in Israel, especially the student population in higher education. The concept of social anxiety and its specific and generalized subtypes is then addressed with reference to the relevant epidemiological and demographic findings and to the problem of the separation between specific and generalized social anxiety subtypes. The following studies discuss the relationship between social anxiety and these subtypes and other social, emotional and educational aspects, such as other anxieties, depression, drug addiction, personality disorders, learning motivation, and self- esteem.

\subsection{The Palestinian Arab minority in Israel}

When the State of Israel was established after the war in 1948, only 156,000 Palestinian Arab residents remained. This figure represents $13 \%$ of the new state's population. The Palestinian Arab minority in Israel are an indigenous group with unique characteristics. They were the majority during the Palestine mandate, and became a minority overnight as a result of the exodus of a large proportion of the Palestinian Arabs. This is known among the Palestinian Arab minority in Israel as the "Nakba". This complex situation had an impact on the policies toward the Arab population. The first characteristic of Palestinian Arab minority in Israel is that unlike other minority population, this is not an immigrant minority, but a minority of local people (Abu-Saad, 2006).

The Arab population in Israel is, at the same time, a numerical minority and a sociological minority. They are a sociological minority because this is a population sector that is not represented in the political elite. At the same time, they are not represented in the military elite nor in the country's economic elite. Therefore, they are deprived of the 
national dominant group. The Arab population was left with no infrastructure for the creation and nourishment of Arab culture and without channels for the Arab mother culture. The first channel for the Arab world was not opened until after the 1967 war and after the opening of the borders when additional channels were opened following the peace agreements (Abu Asbeh, 2007).

Today, according to the Central Bureau of Statistics, the Palestinian Arab population comprises $21 \%$ of the Israeli population. The group is divided as follows: Moslems (70\%), Christians (21\%) and Druze (9\%) (CBS, 2018). While they still suffer from policies of discrimination, as well as social control and marginalization, the Palestinian Arab minority in Israel has managed to narrow the gaps between themselves and the Jews in all spheres: political, economic, social, cultural and especially in education. One of the reasons a significant gap continues to exists between Arab and Jewish citizens, in the educational field, is due, in-part, to the teaching methods and learning skills in Arab society schools relative to schools in Jewish sectors. In Arab society, the teaching method does not encourage critical and independent thinking patterns. In addition, the study suggests that, in Arab society, schools have the expectation that the Arab student should receive assistance from teachers in coping with learning difficulties (Agbaria, Mustafa, \& Jabreen, 2015; Gharrah, 2016). These characteristics become a double obstacle in higher education - once in the study itself, when the nature of the learning in the schools does not prepare the Arab student for the skills required in the higher studies, and once again with the expectations of the students and the lecturers (Arar, 2016).

Furthermore, the context of culture, gender, political affiliation, socio-economic and religious status all have a decisive influence on the way Palestinian Arab minority in Israel young people experience the period of young adulthood and how they deal with stress and anxiety and thus derive their needs during this period. These and other cultural issues influence the degree of individualism in the Palestinian Arab minority society in Israel, the existence of the mechanisms for the placement of young men and women, and the various expectations of them. These conditions influence the level of uncertainty, fears, anxieties, and pressures that will confront them not only during the transition to adulthood, but also in their transition to higher education (Shohami, 2014).

Moreover, it can be seen that the Palestinian Arab minority students in Israel who study in higher education encounter all sorts of language-related difficulties that cause fear, pressure, indecision and frustration as well as difficulty in integrating with Jewish students. It can be seen that some Arab students have problems with the ability to express themselves in comparison to their Jewish counterparts. This has many negative implications, which affects how the students appear to the lecturers, to the dominant population, and can lead to their failure in higher education (Amara, Donitza-Schmidt, \& Mari, 2016; Shilli, 2014).

\subsection{Social Anxiety: Epidemiological and Demographic Findings}

Scientific literature distinguishes between four main factors of stressors and anxieties among students:

a. External pressures: includes stressful events that are not directly related to studies and can occur with any person, or events that combine external requirements with studies;

b. Academic pressures: includes stressful events that are directly related to the student's educational experiences in various fields;

c. Public fear: includes stressful events related to the learning experience, but all are focused on the fear of evaluating from others who are watching the student in test situations;

d. Loneliness: includes events that create a sense of loneliness, most of which are not directly related to educational experiences (Segal, \& Ezer, 2009).

The Diagnostic and Statistical Manual of Mental Disorders ("DSM-5") published by the American Psychiatric Association, 2013, defines social anxiety as "an excessive fear of criticism, social rejection and ridicule in social situations. These fears are so frequent and powerful that they cause distress and obvious functional impairment." The DSM-5 refers to two subtypes of social anxiety: a. Specific Social Anxiety: excessive fear of one, two or three social situations requiring performance and social interaction with others; b. Generalized Social Anxiety: excessive fear of most social situations requiring performance and social interaction with others. Social anxiety has also been defined as the "fear of negative evaluation by others in a variety of social situations" (Bjornsson et al., 2011; Obeid, Buchholz, Boerner, Henderson, \& Norris, 2013), which require performance and social interaction with others.

Social anxiety often occurs in conjunction with other anxiety disorders, in particular, generalized anxiety. Social anxiety is differentiated from other disorders by excessive fear, avoidance of a large number of social interactions and its negative impact on the daily lives of sufferers caused by their social phobias (Dryman, \& Heimberg, 2015; Yap, Gibbs, Francis, \& Schuster, 2016). Social anxiety can affect $2 \%$ of the general population (Turner, \& Beidel, 1989) and is the second most common anxiety disorder after agoraphobia (Beesdo-Baum et al., 2012). The disorder is usually accompanied by comorbidity, disability and impaired psychological functioning (Beesdo-Baum et al., 2012). 
The relative prevalence of the two subtypes of social anxiety - specific and generalized -varies from study to study because of differences in the nationality of the population, methodological aspects, the techniques used to categorize the two types and differing assessment methods. For example, a study by Rabe-Jablonska, Dietrich-Muszalska, \& Gmitrowicz, 2004, found that $7 \%$ of adolescents had generalized social anxiety and $17 \%$ had specific social anxiety. In contrast, the researchers (Zubeidat, Salinas, Sierra, \& Fernández-Parra), reported rates of 3.95\% of generalized social anxiety and $4.47 \%$ of specific social anxiety among adolescents.

Most of the studies conducted on adult populations indicate that individuals with social anxiety are characterized by low socioeconomic status and unstable employment. High percentages are single, women and students (Davidson, Hughes, George \& Blazer, 1993; Jimenez, Sáiz, Bascarán, \& Iglesias, 1999; Magee, Eaton, Wittchen, McGonagle, \& Kessler, 1996; Kupper, \& Denollet, 2012; Patel, Knapp, Henderson \& Baldwin, 2002). Furthermore, despite the fact that the percentages of women are higher than those of men in almost all types of anxiety and phobia disorders, the difference in the prevalence of social anxiety among men and women is unclear, since some studies have found that among females it is sometimes only slightly higher than among males (Myers, Weissman, \& Tischler, 1984). In contrast, others report equal incidences of social anxiety between the two genders (Amies, Gelder, \& Shaw, 1983). Specifically, it was found that social anxiety leads to poor school performance, a higher incidence of unemployment (Wittchen, Stein, \& Kessler, 1999) and difficulties in family relationships (Peleg, 2005).

Marital status is considered to be significant in social anxiety disorders, since it was found that $38 \%$ of women suffering from social anxiety were unmarried (Amies et al., 1983). In this regard, most studies report a higher percentage of singles among individuals with social anxiety than among those without social anxiety (Davidson et al., 1993; Kupper, \& Denollet, 2012). Moreover, the results of epidemiological studies all indicate that individuals with social anxiety have low socioeconomic and social status (Davidson et al., 1993; Kupper, \& Denollet, 2012; Wittchen et al., 1999). Social anxiety often starts before other anxiety disorders and it can appear at the end of childhood or at the onset of adolescence, and only rarely after the age of 25 (La Greca, Ingles, \& Lay, 2015; Weiller, Bisserbé, Boyer, Lépine, \& Lecrubier, 1996) or between the ages of 15 and 20 (Koyuncu et al., 2015).

\subsection{Relationships Between Subtypes of Social Anxiety and Social-Emotional Aspects}

The studies which examined the relationship between social anxiety and other disorders used adult populations and found that most of the problems which overlapped with social anxiety are other anxieties (Faravelli et al., 2000; Magee et al., 1996) depression (Faravelli et al., 2000; Pini et al., 1997; Wilson, \& Rapee, 2005) drug use (Galbraith et al., 2013) social deprivation and antisocial behaviour (Lim, Rodebaugh, Gleeson, \& Zyphur, 2016; Pacek et al., 2013) and feelings of inferiority and low self-esteem (Baños, \& Guillén, 2000; Leary, \& Kowalski, 1995). Other studies have shown that anxiety disorders manifest themselves together with depression, oppositional-defiant disorder, ADHD and drug and alcohol use (Essau, Conradt, \& Petermann, 2000; Lewinsohn, Zinbarg, Seeley, Lewinsohn, \& Sack, 1997).

The scientific literature contains some research into the differences between specific social anxiety and generalized social anxiety in respect of their prevalence and relationship with demographic variables, their links to behavioural disorders and other mental disorders and the differences between them in performance and interaction situations. Most of these studies were conducted on adults (Faravelli et al., 2000; Nagata, Suzuki, \& Teo, 2015; Olivares, Piqueras, \& Sánchez-García, 2004). In any event the separation between specific social anxiety and generalized social anxiety is unclear, among both adult and adolescent populations (Heimberg, Holt, Schneier, Spitzer, \& Liebowitz, 1993; Hofmann et al., 1999).

Various studies have reported on differences between specific social anxiety and generalized social anxiety with comorbidity. These differences indicate that generalized social anxiety is associated with a higher degree of comorbidity than specific social anxiety and with other anxiety disorders (for example, agoraphobia, panic disorder), mood disorders (for example, depression) alcoholism and drug use and personality disorders (for example, schizophrenia) (Faravelli et al., 2000; Mannuzza et al., 1995). These individuals exhibit low levels of self-esteem and high levels of depression, neurotic problems, anxiety, history of childhood shyness and deficient social skills (Hofmann \& Roth, 1996; Lim et al., 2016). The researchers Chavira, Stein, Bailey, \& Stein, 2004, reported high comorbidity between generalized social anxiety and depression, generalized anxiety and specific phobias.

Other concepts such as motivation for learning and self-esteem are also linked to social anxiety (Olivares et al., 2004). Motivation for learning is an important component in the learning process. In recent decades there has been increased recognition of the key role played by motivation processes in the academic success of students (Hyunjin, \& YoonJun, 2014; Jianzhong, 2014). The term "self-esteem" has been defined as "an organized system of traits which individuals believe they possess and which govern their behaviour" (Fitts, 1965). Taylor, Wooten, Babcock, \& Hill, 2002 regard self-esteem as both a factor in and a result of social-cultural factors, whereas other researchers (Carlson, Uppal, \& Prosser, 2000; Muldoon, \& Trew, 2000) add that self-esteem is also perceived as the individual's evaluation of his 
membership of an ethnic group as well as a measure of social acceptance and emotional experiences.

Social anxiety also is associated with impaired development of social skills, a significant decline in social interactions, low self-esteem and poor educational performance. Social anxiety has a significant impact on the daily functioning of sufferers. For example, Bjornsson et al. (2011) note that social anxiety leads to a significant increase in suicidal intentions among sufferers.

\subsection{Rationale and Importance of Research}

In conclusion, social anxiety is an excessive fear of situations requiring social interaction. Social anxiety is one of the most common social disorders in child and adolescent populations. Most of the studies conducted on social anxiety used models of adults in both American and European populations. There are consequently few studies of Palestinian Arab student teachers in Israeli society, and this is what prompted us to carry out the current study. Furthermore, the research literature demonstrates that there is a link between social anxiety and a range of social-emotional and educational aspects which attest to the negative ramifications of this disorder for various domains in life. Individuals with this problem therefore need treatment in order to improve their adjustment to their natural environment.

In this current study, we choose a sample of Palestinian Arab minority in Israel student teachers from academic colleges for teacher education. This is a multicultural minority that includes students of education with a diverse ethnic-religious background (Muslims, Christians and Druze) and undergoes a process of socialization that includes a variety of difficulties and pressures that characterize the Israeli educational system in general and the Arab education system in particular. Without a doubt, this is an innovative and unique study due to its unique model, which is characterized by special social-emotional, educational, systemic and political aspects. Due to the uniqueness of the student population of colleges for teacher's education, it is important to investigate the subject of social anxiety (including its subtypes) and its relationship with these aspects, while relating to the Israeli educational system.

It is important to note that teaching students will constitute the future teacher population in primary and high schools; therefore, it is interesting to examine their levels of social anxiety and the implications of these levels on their performance during their future vocational and school training process. At the same time, special attention needs to be given to intervention programs aimed at reducing these levels of social anxiety and enabling an optimal absorption the future Palestinian Arab minority teachers in Israel.

\section{Methodology}

\subsection{Objective and Hypotheses of the Study}

The uncertainty surrounding the definition of the term "social anxiety" (particularly generalized social anxiety), the epidemiology and psychopathology of this disorder and its subtypes, both specific and generalized, as well as the lack of identification of the demographic, social-emotional and educational differences among persons with specific and generalized social anxiety led to this study.

This study is unique in its sampling because most of the studies conducted on this topic used clinical samples of adults and adolescents outside the educational framework, whereas this one selected a sample of student teachers from various places and cultures from Arab minority in the north of Israel. In other words, since this is a topic which has not been studied in Israeli colleges or among student teachers from Arab minority in Israel, it is therefore an innovation in this area. Its results have caused the researchers to discuss the ramifications of the above-mentioned aspects of the student-teacher educational environment. The hypotheses of this study are therefore as follows:

1. There are more student teachers with specific social anxiety than with generalized social anxiety.

2. There are positive correlations between specific social anxiety and generalized social anxiety and between social fear, social avoidance and depression, and negative correlations between them and motivation for learning, self-esteem and perceived social and family support.

3. There are differences between student teachers with specific social anxiety and those with generalized social anxiety based on the demographic variables of gender, age, study track, work, family status, income level and religious-ethnic background.

4. Student teachers with specific social anxiety will demonstrate lower levels of social anxiety, social fear, social avoidance and depression and higher levels of motivation for learning, self-esteem and perceived social and family support than student teachers with generalized social anxiety.

5. There are correlations between levels of social anxiety (specific and generalized) and between levels of depression, self-esteem, motivation for learning and perceived social and family support. 


\subsection{Participants}

The participants in the study are Palestinian Arab minority student teachers from teacher education colleges in north Israel enrolled in different tracks: pre-academic preparatory studies, conditional, regular track, graduate and vocational training and continuing studies from various departments (Arabic, English, mathematics, early childhood and special education). All the participants are native Arabic speakers and a large majority are studying for a bachelor's degree. They were selected by the researchers in a random cluster sampling. The sample consists of 543 student teachers. Table 1 presents the personal demographic characteristics of the sample.

Table 1. Personal demographic characteristics of the sample $(\mathrm{N}=543)$

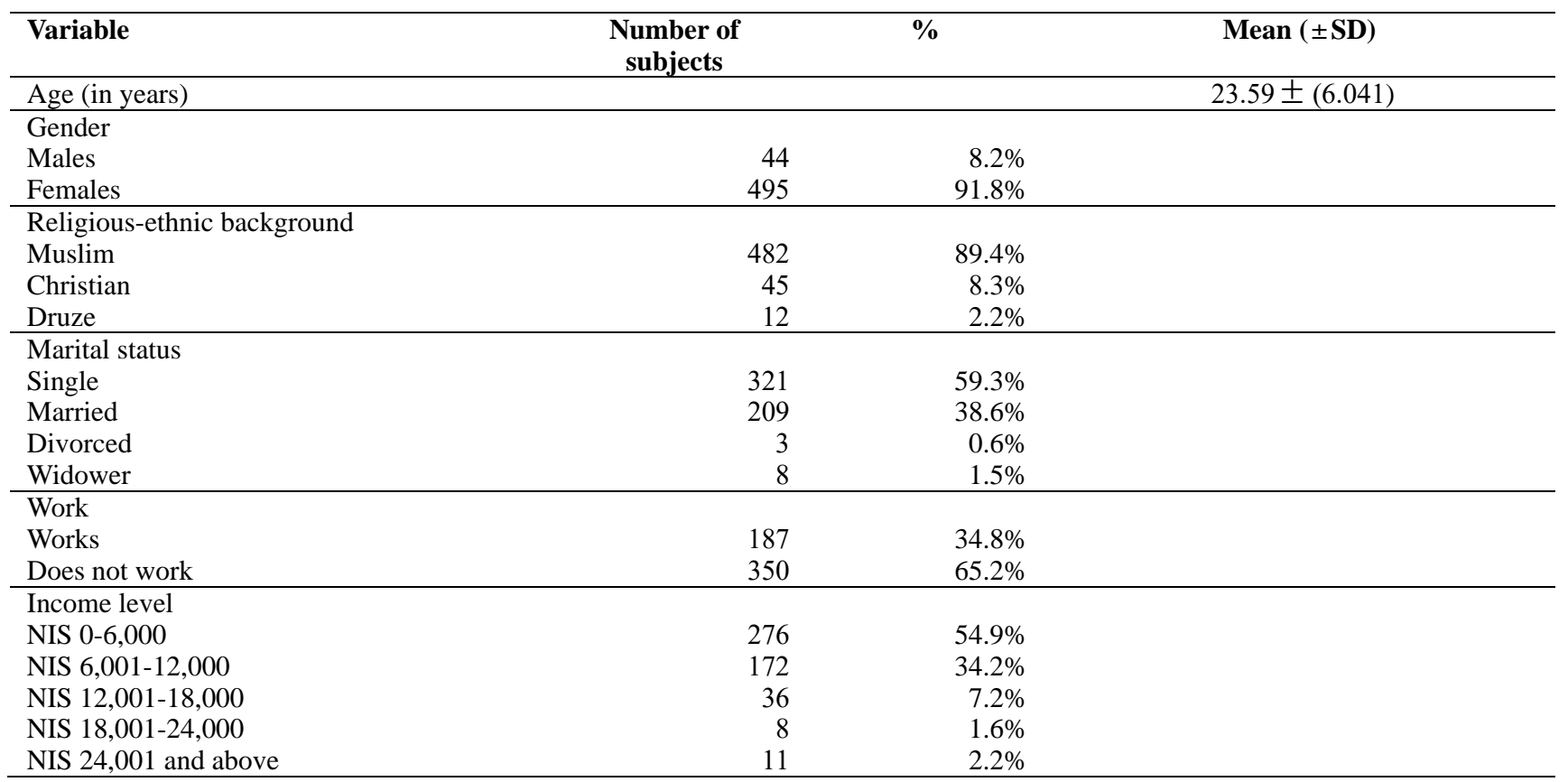

There were also other demographic variables which depend on the studies of the student teachers in the sample. Table 2 presents these characteristics.

Table 2. Personal demographic characteristics of the sample $(\mathrm{N}=543)$

\begin{tabular}{|c|c|c|}
\hline Variable & Number of subjects & $\%$ \\
\hline \multicolumn{3}{|l|}{ Study framework } \\
\hline Regular & 305 & $56.2 \%$ \\
\hline Retraining and continuing education & 50 & $9.2 \%$ \\
\hline Conditional & 76 & $14 \%$ \\
\hline Pre-academic preparatory program & 49 & $9 \%$ \\
\hline Graduate & 63 & $11.6 \%$ \\
\hline \multicolumn{3}{|l|}{ Specialty } \\
\hline English & 92 & $29.1 \%$ \\
\hline Mathematics & 55 & $17.4 \%$ \\
\hline Arabic & 18 & $5.7 \%$ \\
\hline Special education & 36 & $11.4 \%$ \\
\hline Sciences & 58 & $18.4 \%$ \\
\hline Early childhood & 57 & \\
\hline \multicolumn{3}{|l|}{ Academic year } \\
\hline Year 1 & 118 & $42.6 \%$ \\
\hline Year 2 & 59 & $21.3 \%$ \\
\hline Year 3 & 71 & $25.6 \%$ \\
\hline Year 4 & 29 & $10.3 \%$ \\
\hline
\end{tabular}

\subsection{Type of the Study and Its Variables}

This is a quantitative correlational study which attempts on the one hand to examine the various demographic, social-emotional and educational differences which distinguish between student teachers with specific and generalized social anxiety, and on the other hand to examine the relationships between specific and generalized social anxiety and depression, self-esteem, motivation for learning and perceived social and family support. The social anxiety is measured on a Likert scale and the variable is a continuous variable. The dependent variable is therefore the level of social anxiety while the independent variables are gender, age, study track, academic year, work, marital status, socioeconomic status, 
religious-ethnic background, social fear, social avoidance, depression, motivation for learning, self-esteem and perceived social and family support.

\subsection{Study tools}

The questionnaires given to the participants were as follows:

\subsubsection{Profile and Background Data}

This questionnaire contains some demographic background variables relating to the participants such as gender, age, academic year, study track.

\subsubsection{Liebowitz Social Anxiety Scale - (“LSAS”) (Liebowitz, 1987)}

The questionnaire was designed to assess social anxiety and it contains two measures: social fear and social avoidance of social situations. It contains 24 items (13 of which describe performance situations and 11 which describe social interaction situations). Each statement of fear/anxiety is scored separately on a scale from 0 (none) to 4 (severe) and social avoidance on a scale from 0 (never) to 4 (usually). For example, "going to a party" or "delivering a speech in public". The higher the score, the greater the degree of the respondent's social anxiety. The final grade will be calculated as an average of the subject's responses. The internal reliability test of the LSAS found that Cronbach's alpha $=0.94$. The internal reliability of the two components of this questionnaire was also tested and it was found that the reliability of the first (social fear) was 0.91 while the reliability of the second (social avoidance) was 0.89 .

\subsubsection{Beck Depression Inventory - (“BDI”) (Beck, Ward, Mendelson, Mock, \& Erbaugh, 1961)}

This is one of the most widely used tools for measuring the severity of depression. Developed by Aaron Beck, the creator of the cognitive therapy approach, it is based on a multiple-choice questionnaire consisting of 21 questions which are self-reported by the subject. The answers were assessed using the Likert scale from 0 to 3 . For example, "I don't cry any more than usual" or "I don't have any thoughts of killing myself". The BDI version used today was intended for subjects aged 13 and up and contains symptoms of depression such as hopelessness and irritability, feelings of guilt and punishment, tiredness, weight loss, loss of interest in sex. The internal reliability test of this questionnaire found that Cronbach's alpha $=0.77$.

\subsubsection{Motivation for Learning Questionnaire}

The questionnaire consists of 15 items taken from the Motivated Strategies for Learning Questionnaire ("MSLQ") which was developed by Pintrick, Smith, Garcia, \& McKeachie, 1991. The answers were assessed using a 7-point Likert scale where 1 is "not at all true of me" while 7 is "very true of me". For example, "I am very interested in what we are learning in this class" or "It is very important for me to understand what is being taught in this class". The questionnaire measures the motivational beliefs relating to learning in a particular class and also examines the learning strategies of the students in that class. The objective of the questionnaire is to assess the motivation for learning of the students. The questionnaire measures three elements: intrinsic achievement orientation, task value and critical thinking. The internal reliability test of this questionnaire found that Cronbach's alpha $=0.88$.

\subsubsection{Rosenberg Self-Esteem Questionnaire (“RSEQ”) (Rosenberg, 1965)}

This is a ten-item scale which measures self-esteem. The participants are asked to express their agreement with statements, without stopping, on a Likert scale from 1 to 4 where 1 is "strongly agree" and 4 is "strongly disagree". For example, "I feel I have a number of positive qualities" or "I wish I had more self-esteem". An analysis of the questionnaire presents two elements: positive self-esteem and negative self-esteem. It is important to note that the scale was reversed for items 3, 5, 8, 9 and 10 in this questionnaire. The internal reliability test of this questionnaire found that Cronbach's alpha $=0.76$.

\subsubsection{The Multidimensional Scale of Perceived Social Support (“MSPSS”) (Zimet, Dahlem, Zimet, \& Farley, 1988)}

This is a questionnaire comprising 12 statements which examine the subjective perception of the respondents regarding the degree of social and family support available to them from three sources - family (includes items 3,4 and 8), friends (includes items 6, 7 and 9) and significant others (includes items 1,2, 5 and 10). Use of this questionnaire produces three measures based on the averages for each item, so that the scores range between 1 and 7 . The higher the score, the greater the perceived degree of social and family support. The answers were assessed on a 7-item scale where 1 is "Extremely applicable" and 7 is "Extremely inapplicable". For example, "my family really tries to help me" or "there is a person close to me who cares about my feelings". The internal reliability test of this questionnaire found that Cronbach's alpha $=0.91$.

The current research tools that the students used to respond were written in Hebrew. We did not see the necessity in translating these tools into Arabic, since we assume that Arab student teachers can deal well with Hebrew 
questionnaires. In addition, the researchers were present when filling out the questionnaire and answered questions when necessary.

\subsection{Procedure}

The researchers contacted Palestinian Arab minority student teachers in Israel, explained the goals and objectives of the study and asked if they would respond to the questionnaires. The data were collected by the researchers while they were in college but not during lecture times. They explained to the participants how to fill in the questionnaires without interfering in or influencing their responses. After the questionnaires had been filled in by the students they were sent to the researchers for subsequent encoding and analysis. For ethical reasons, it was explained to the participants that this study is completely anonymous, and that the data they provided would be used for this specific study and would not sent to any third parties.

\subsection{Data Processing and Analyses}

Following the data-gathering process, the researches reviewed the validity and internal reliability (Cronbach's Alpha) of the study questionnaires. These are the statistical analyses for which the research hypotheses were tested:

1. Comparison between the student teachers with specific social anxiety and those with generalized social anxiety from various demographic, emotional-social and educational aspects (using Mann-Whitney tests for two independent samples and a t test).

2. Explore the relationships between specific social anxiety and generalized social anxiety levels and levels of depression, self-image, motivation for learning and perceived social and family support using the $\chi^{2}$ test and the Pearson test.

3. Construction of regression models of the social anxiety (specific and generalized) variable from various demographic, emotional-social and educational aspects.

\section{Findings}

In order to examine the differences in social anxiety based on the age variable, the subjects were divided into two groups. (A) "Young" student teachers born in and after 1990. (B) "Adult" students born before 1990. Palestinian Arab minority student teachers in Israel born before 1990 are considered young because they studied during the first years of their careers, while others born after 1990 are perceived as adults because they constitute the population of student teachers who are in their last years of training, especially those who are in the third year or induction year. A test was conducted on independent samples, as presented in Table 3.

Table 3. Comparison between young and adult students at the social anxiety level $(\mathrm{N}=543)$

\begin{tabular}{cccccc}
\hline Area & Group & N & Mean & $\begin{array}{c}\text { Standard } \\
\text { deviation }\end{array}$ & t \\
\hline Social anxiety & Adult & 131 & 0.88 & 0.53 & $2.51^{*}$ \\
& Young & 392 & 1 & 0.46 & \\
\hline
\end{tabular}

$(* p<0.05)$

The findings presented in Table 3 indicate a statistically significant difference between the mean values in the social anxiety dimension $(t(521)=2.51, p<0.05)$. The social anxiety mean value among the young subjects was found to be higher than the social anxiety mean value among the adult subjects. The participants in the study were also divided into two groups in order to examine the social anxiety differences based on the gender variable: men student teachers $(\mathrm{N}=44)$ and women student teachers $(\mathrm{N}=495)$. The findings indicated that there is no difference in the social anxiety level mean value based on this variable.

The subjects were also divided into three categories at the social anxiety level based on a quantitative criterion for the Liebowitz Social Anxiety Scale. Students with no social anxiety received grades below the mean and standard deviation. Students with specific social anxiety received grades higher than the mean and a 1-1.5 standard deviation, while students with generalized social anxiety received grades higher than the mean and a 1.5 standard deviation, as illustrated in Table 4. 
Table 4. Breakdown of levels of social anxiety among the three study categories $(\mathrm{N}=543)$

\begin{tabular}{lcc}
\hline Category & Number & Percentage \\
\hline Student teachers without social anxiety & 454 & $83.4 \%$ \\
Student teachers with specific social anxiety & 55 & $10.1 \%$ \\
Student teachers with generalized social anxiety & 34 & $6.3 \%$ \\
\hline
\end{tabular}

The findings of the study have been described based on the various hypotheses, as follows:

First hypothesis: there are more student teachers with specific social anxiety than with generalized social anxiety.

The study's findings as illustrated in Table 4 indicate that the category of student teachers with specific social anxiety $(\mathrm{N}=55 ; 10.1 \%)$ was more prevalent than the category of student teachers with generalized social anxiety $(\mathrm{N}=34 ; 6.3 \%)$, meaning that the first hypothesis of the study has been substantiated.

Second hypothesis: there are positive links between specific social anxiety and generalized social anxiety and social fear, social avoidance and depression, and negative links between them and motivation for learning, self-esteem and perceived social and family support.

The correlations were tested by Pearson's correlation coefficient, as described in Table 5:

Table 5. The correlation coefficients between specific and generalized social anxiety and between various social-emotional and educational aspects $(\mathrm{N}=89)$

\begin{tabular}{llllllll}
\hline & & $\begin{array}{c}\text { Social } \\
\text { Fear }\end{array}$ & $\begin{array}{c}\text { Social } \\
\text { Avoidance }\end{array}$ & Depression & $\begin{array}{c}\text { Motivation for } \\
\text { learning }\end{array}$ & $\begin{array}{c}\text { Self-esteem } \\
\text { Perceived social and } \\
\text { family support }\end{array}$ \\
\hline $\begin{array}{l}\text { Specific } \\
\text { anxiety }\end{array}$ & social & $0.36^{* *}$ & 0.195 & 0.107 & -0.059 & -0.130 & $-0.272^{*}$ \\
\hline $\begin{array}{l}\text { Generalized } \\
\text { anxiety }\end{array}$ & social & $0.823^{* * *}$ & $0.771^{* * *}$ & $0.386^{*}$ & 0.190 & 0.111 & 0.059 \\
\hline
\end{tabular}

$(* * p<0.01) \quad(* * * p<0.001) \quad(* p<0.05)$

The findings presented in Table 5 reveal the following:

1. A statistically significant positive link between the specific social anxiety of the subject and his social fear $\left(r_{p}=0.36, p<0.01\right)$ so that the greater the specific social anxiety of the subject, the greater his social fear.

2. A statistically significant negative link between the specific social anxiety of the subject and between his perceived social and family support $\left(r_{p}=-0.272, p<0.05\right)$ so that the greater the perceived social and family support of the subject, the lower his specific social anxiety.

3. A statistically significant positive link between the high specific social anxiety of the subject and between his social fear level $\left(r_{p}=0.823, p<0.001\right)$ so that the higher the social anxiety of the subject, the higher his social fear level.

4. A statistically significant positive link between the generalized social anxiety of the subject and his social avoidance level $\left(r_{p}=0.771, p<0.001\right)$ so that the higher the generalized social anxiety of the subject, the higher his social avoidance level.

5. A statistically significant positive link between the generalized social anxiety of the subject and his depression level $\left(r_{p}=-0.386, \quad p<0.05\right)$ so that the higher the generalized social anxiety of the subject the higher his depression level. The second hypothesis was partly substantiated.

Third hypothesis: there are differences between student teachers with specific social anxiety and student teachers with generalized social anxiety based on the demographic variables: gender, age, study track, work, marital 


\section{status, income level and religious-ethnic background.}

The differences between specific social anxiety and generalized social anxiety were examined in relation to various demographic variables using Mann-Whitney tests on two independent samples (because the independent variable was categorical). The findings indicated a statistically significant difference between the two groups in the age dimension only. The findings indicate a statistically significant difference between the two groups of social anxiety $(z=-2.22, \quad p<0.05)$ The average age among student teachers with generalized social anxiety $(M=24.78, \quad S D=5.24)$

was found to be higher than the average age among student teachers with specific

social anxiety $(M=23.12, S D=3.70)$.

Furthermore, the differences between the averages of student teachers with specific social anxiety and the student teachers with generalized social anxiety were examined in relation to the other demographical variables. The differences were tested using t tests and F tests. The findings indicated that there are no differences between the two social anxiety groups in all the above variables. The third hypothesis was partly substantiated.

Fourth hypothesis: student teachers with specific social anxiety will demonstrate lower levels of social anxiety, social fear, social avoidance and depression and higher levels of motivation for learning, self-esteem and perceived social and family support than student teachers with generalized social anxiety.

T-tests using two independent samples were conducted on the differences between specific social anxiety and generalized social anxiety in relation to the social-emotional and educational aspects. The findings indicated a statistically significant difference between the two groups of social anxiety in only three dimensions (social anxiety, social fear and social avoidance), as presented in Table 6.

Table 6. Results of the t-tests conducted to examine the differences between generalized social anxiety and social anxiety in relation to the various social-emotional and educational aspects $(\mathrm{N}=89)$

\begin{tabular}{|c|c|c|c|c|c|}
\hline Aspect & Category & $\mathbf{N}$ & Mean & Standard deviation & $\mathbf{t}$ \\
\hline \multirow[t]{2}{*}{ Social anxiety } & Generalized social anxiety & 34 & 1.99 & 0.29 & \\
\hline & Specific social anxiety & 55 & 1.55 & 0.06 & $8.677 * * *$ \\
\hline \multirow[t]{2}{*}{ Social fear } & Generalized social anxiety & 34 & 2.05 & 0.30 & \\
\hline & Specific social anxiety & 55 & 1.58 & 0.22 & $8.433 * * *$ \\
\hline \multirow[t]{2}{*}{ Social avoidance } & Generalized social anxiety & 34 & 1.89 & 0.47 & \\
\hline & Specific social anxiety & 52 & 1.52 & 0.22 & $4.329 * * *$ \\
\hline
\end{tabular}

$(* * * p<0.001)$

The findings presented in Table 6 reveal the following:

A statistically significant difference between the mean values in the social anxiety dimension $(t(87)=8.677, \quad p<0.001)$. The mean specific social anxiety among the subjects with generalized social anxiety was found to be higher than the mean social anxiety level among the subjects with specific social anxiety.

A statistically significant difference between the mean values in the social fear dimension $(t(87)=8.433, \quad p<0.001)$. The mean social fear level among the subjects with generalized social anxiety was found to be higher than the mean social fear level among the subjects with specific social anxiety.

A statistically significant difference between the mean values in the social avoidance dimension $(t(84)=4.329, \quad p<0.001)$. The mean social avoidance level among the subjects with generalized social anxiety was found to be higher than the mean social avoidance level among the subjects with specific social anxiety. 
Moreover, t-tests were conducted on the differences between the means of student teachers with generalized social anxiety and the student teachers with specific social anxiety in relation to the depression, motivation for learning, self-esteem and perceived social and family support variables. The findings indicated that there are no differences in all the above variables and dimensions. These findings partly substantiate the fourth hypothesis.

Fifth hypothesis: there are links between levels of social anxiety (specific and generalized) and between levels of depression, self-esteem, motivation for learning, and perceived social and family support.

Tests were conducted on percentage breakdowns and links between a two-dimensional breakdown of levels of social anxiety crossed with levels of depression, self- esteem, motivation for learning and perceived social and family support as described in Table 7.

Table 7. Breakdown of subjects by levels of depression, self-image, motivation for learning, perceived social and family support and social anxiety levels $(\mathrm{N}=543)$

\begin{tabular}{|c|c|c|c|c|c|c|c|}
\hline \multirow{2}{*}{\multicolumn{2}{|c|}{$\begin{array}{l}\text { Various social-emotional and educational } \\
\text { aspects and levels of social anxiety }\end{array}$}} & \multicolumn{5}{|c|}{$\mathbf{N}(\%)$} & \multirow{3}{*}{$\chi^{2}$} \\
\hline & & No anxiety & $\begin{array}{l}\text { Specific } \\
\text { anxiety }\end{array}$ & social & $\begin{array}{l}\text { Generalized } \\
\text { anxiety }\end{array}$ & \multirow[t]{2}{*}{ social } & \\
\hline \multirow[t]{2}{*}{ Depression } & No depression & (77) 418 & $(7.7) \quad 42$ & & $(5.5) \quad 30$ & & \\
\hline & With depression & (6.6) 36 & (2.4) 13 & & $(0.7) 4$ & & $13.91 * *$ \\
\hline \multirow[b]{2}{*}{ Self-esteem } & Normal & (79) 429 & (9.6) 52 & & (6.3) 34 & & \multirow[b]{2}{*}{19.97} \\
\hline & Low & (4.6) 25 & $(0.6) 3$ & & (0) 0 & & \\
\hline \multirow{3}{*}{$\begin{array}{l}\text { Motivation } \\
\text { learning }\end{array}$} & High & (10.1) 55 & (2.4) 13 & & (1.5) 8 & & \multirow[b]{3}{*}{$14.014 * *$} \\
\hline & Normal & (63.5) 345 & (7.7) 42 & & (4.2) 23 & & \\
\hline & Low & (9.9) 54 & (0) 0 & & $(0.6) 3$ & & \\
\hline \multirow{3}{*}{$\begin{array}{l}\text { Perceived social } \\
\text { and family support }\end{array}$} & High & (10.5) 57 & $(1.1) 6$ & & $(0.4) 2$ & & \multirow[b]{3}{*}{3.383} \\
\hline & Average & (61.1) 332 & (7.2) 39 & & (4.4) 24 & & \\
\hline & Low & (12) 65 & (1.8) 10 & & (1.5) 8 & & \\
\hline
\end{tabular}

$(* * p<0.01)$

The findings in Table 7 indicated that there is a statistically significant link between levels of depression and levels of social anxiety $\left(\chi^{2}(2)=13.906, p<0.01\right)$, and a statistically significant association between levels of motivation for learning and social anxiety $\left(\chi^{2}(4)=14.014, p<0.01\right)$ while there are no statistically significant links between levels of social anxiety and self- esteem $\left(\chi^{2}(2)=1.972, p>0.05\right)$ and between levels of social anxiety and levels of perceived social and family support $\left(\chi^{2}(4)=3.383, p>0.05\right)$. The fifth hypothesis was partly substantiated.

In order to predict the level of specific social anxiety of a student teacher on the basis of levels of depression, selfesteem, motivation for learning and perceived social and family support, a simple regression model was prepared. The regression analysis reveals that the student's level of specific social anxiety cannot be explained by his level of depression $\quad(F(1,52)=0.604, p>0.05) \quad, \quad$ by $\quad$ his level of self-esteem $(F(1,52)=0.849, \quad p>0.05) \quad, \quad$ or $\quad$ by $\quad$ his level of motivation for learning $(F(1,53)=0.182, \quad p>0.05)$. In contrast, the analysis reveals that the student's level of specific social anxiety can be explained by his level of perceived social and family support $(F(1,52)=4.14, \quad p<0.05)$ and by his age $(F(1,50)=3.67, p<0.05)$. The analysis also reveals that the depression predictor variable 
explained $1.1 \%$, the self- esteem predictor variable explained $1.7 \%$, the motivation for learning predictor variable explained $0.3 \%$, the perceived social and family support predictor variable explained $7.4 \%$ and the age predictor variable explained $30.2 \%$ of the variance of specific social anxiety of the student teachers.

On the other hand, in order to predict the level of generalized social anxiety of a student teacher on the basis of levels of depression, self- esteem, motivation for learning and perceived social and family support a simple regression model was prepared. The regression analysis reveals that the level of the student's generalized social anxiety can be explained on the basis of his level of depression $(F(1,31)=5.44, p<0.05)$ and on the basis of his age $(F(1,30)=12.96, \quad p<0.001)$. In contrast, the analysis reveals that the student's generalized social anxiety cannot be explained by his level of self- esteem $(F(1,32)=0.397, p>0.05)$, his level of motivation for learning $(F(1,32)=1.2, \quad p>0.05)$ or his level of perceived social and family support $(F(1,32)=0.111, p>0.05)$. The analysis also reveals that the depression predictor variable explained $14.9 \%$, the age predictor variable explained $30.2 \%$, the self- esteem predictor variable explained $1.2 \%$, the motivation for learning predictor variable explained $3.6 \%$ and the perceived social and family support variable explained $0.3 \%$ of the variance of the generalized social anxiety of the students.

\section{Discussion and Conclusions}

Social anxiety is considered to be the least researched of the various anxiety disorders. In recent years, an interest in studying this type of anxiety has emerged, in samples of children and adolescents as well as in adults. Various epidemiological studies of social anxiety have been conducted, particularly in clinical populations of adults, in order to investigate its socio-demographic, social-emotional and educational characteristics. Most of the studies used socio-demographic variables such as gender, age, socioeconomic status, marital status, academic situation. These studies found that the social anxiety disorder is frequently linked to other psychopathological disorders such as depression, other anxiety disorders as well as other disorders associated with the use of psychoactive substances (Schneier et al., 2010; Moss, 2013; Stevens, Cludius, Banti, Hermann, \& Gerlach, 2014). This means that an investigation of social anxiety and its links with socio-demographic, social-emotional and educational aspects among student teachers is an innovative step in the academic world because of a lack of studies of this topic, in European and American populations as well as in Israeli populations. Moreover, there is added significance in carrying out a study of this kind among student teachers who are destined to become teachers and educators owing to the importance of their academic, social and personal functioning.

The researchers used random cluster sampling to select a wide Palestinian Arab minority student teacher in Israel sample from conditional, pre-academic preparatory, regular classes, and graduate, retraining and continuing education classes from teacher's education colleges in northern Israel. The conclusions drawn from this study are likely to be generalized to student teachers from northern Palestinian Arab minority in Israel, which comprises Muslims, Christians and Druze. In other words, this study does not permit us to draw conclusions regarding the clinical population of adults who are in the process of assessment, diagnosis and treatment for social anxiety problems. Most of the subjects were students, Muslim, single, not working, and in regular classes. The data were gathered from various questionnaires which measured different demographic variables and social-emotional and educational aspects which were individually reported by the subjects. The reliability and validity of the questionnaires were suited in various studies to varying populations and purposes. The Liebowitz Social Anxiety Scale may be used to interview student teachers with differing levels of specific and generalized social anxiety in these aspects.

In recent years the scientific literature has stressed the fact that in relation to social disorders, it is important to investigate the differences between the characteristics of the specific and generalized subtypes of social anxiety in order to improve our understanding and identify them more accurately. Identification of categories with differing levels of social anxiety in order to differentiate between them is a difficult task, particularly in view of the lack of clear definitions of specific social anxiety and generalized social anxiety in the DSM and owing to the absence of differentiation between their characteristics. This manual defines generalized social anxiety as excessive social fear of 
most social situations without identifying their number. This fact has led different researchers (Furmark, Tillfors, Stattin, Ekselius, \& Fredrikson, 2000; Heimberg et al., 1993; Kessler et al., 1994; Ngata et al., 2015; Olivares et al., 2004; Stein, $\&$ Deutsch, 2003) to propose criteria which differentiate a category for generalized social anxiety which is separate from the category known as specific social anxiety. In other words, these researchers have supplied various criteria to separate these two forms of social anxiety in accordance with their objectives and interests without agreement between them on a common criterion. Most of these attempts used quantitative criteria and there have been fewer attempts to propose qualitative criteria. This has resulted in an accumulation of a range of findings, sometimes contradictory, without agreement among the researchers regarding a homogeneous criterion to integrate these findings. The researchers used populations of adults and adolescents different from the population used in this study, which comprises Palestinian Arab minority student teachers in Israel. The proliferation of the criteria and their weakness in differentiating between subtypes of social anxiety and the few studies conducted in student teacher populations led the researchers in this study to initiate a quantitative criterion based on the Liebowitz Social Anxiety Scale which distinguishes between a type of specific social anxiety and another type of generalized social anxiety as described in the Findings section.

Various epidemiological studies conducted on clinical samples of adults have attempted to find a solution to the problem of distinguishing between the characteristics of specific social anxiety and generalized social anxiety (Faravelli et al., 2000; Magee et al., 1996; Nagata et al., 2015; Pini et al., 1997; Wilson, \& Rapee, 2005; Zubeidat et al., 2007). The researchers focused on diverse topics such as frequency, socio-demographic factors and comorbidity in order to investigate the differentiation between the characteristics of these subtypes. The findings of these researchers were varied and sometimes contradictory because of the use of diverse populations (adults versus adolescents and/or clinical versus normative), differing tools, varying methodological processes and criteria to differentiate between the two forms of social anxiety. It is important to note that in this study the researchers selected variables linked to the academic dynamic in order to distinguish between the two subtypes of social anxiety such as social fear, social avoidance, depression, self-esteem, motivation for learning and perceived social and family support. In addition, the proliferation of criteria and their flawed differentiation between specific social anxiety and generalized social anxiety in populations of adults and adolescents (normative and clinical), the few studies of populations of student teachers and the use of different methodological processes of the above-mentioned researchers, prompted the researchers to define their own clear criterion.

Use of this criterion enabled the identification of 89 (16.4\%) student teachers with social anxiety, of whom 55 (10.1\%) comprised groups of student teachers with specific social anxiety, while the remaining $34(6.3 \%)$ were defined as student teachers with generalized social anxiety. The first findings indicated that the mean of social anxiety among the young subjects was found to be higher than the mean of social anxiety among adult subjects, while no difference was found in the mean of social anxiety based on gender. These findings are similar to the findings from various studies which reported higher levels of social anxiety among young people than among adults and no differences or no statistically significant differences in levels of social anxiety between men and women (Amies et al., 1983; Davidson et al., 1993; Magee et al., 1996; Myers et al., 1984; Weiller et al., 1996; Zubeidat et ak., 2007). In this regard, Ranta et al., 2012, found that there are no gender differences in social anxiety among Finnish adolescents. There were more occurrences of specific and generalized social anxiety than those found in other studies (Olivares et al., 2004; Essau et al., 2000, Wittchen et al., 1999; Zubeidat et al., 2007) and this indicates that social anxiety and pressure are more widespread among Palestinian Arab minority student teachers in Israel. Nevertheless, as with the majority of the above-mentioned studies, the incidence of the group of student teachers with specific social anxiety was higher than the incidence of the group of student teachers with generalized social anxiety, which substantiates the first hypothesis of this study. In this context, Rabe-Jablonska et al., 2004, report that 7\% of adolescents have generalized social anxiety compared with $17 \%$ who have specific social anxiety, while other studies (Furmark et al., 2000; Stein, Torgrud, \& Walker 2000) of adults found that specific social anxiety was significantly more widespread than generalized social anxiety.

In contrast, a test was conducted on the second hypothesis which argues that there are statistically significant positive correlations between specific and generalized social anxiety and social fear, social avoidance and depression and statistically significant negative correlations between them and motivation for learning, self-esteem and perceived social and family support. The findings pointed to a statistically significant positive correlation between specific social anxiety and social fear, and a statistically significant negative correlation between specific social anxiety and perceived social and family support. In other words, the higher the level of social fear the higher the level of the student's specific social anxiety, while the lower the level of perceived social and family support, the higher his level of specific social anxiety. This finding corresponds with previous findings which pointed to a negative correlation between social anxiety and low perceived social support and feelings of inferiority (Leary, \& Kowalski, 1995), and a statistically significant positive 
correlation between social anxiety and social fear and social avoidance (Bjornsson et al., 2011; Zubeidat et al., 2007). The findings also pointed to a statistically significant positive correlation between generalized social anxiety and social fear, social avoidance and depression. In other words, the higher the level of social fear, social avoidance and depression, the higher the level of generalized social anxiety. In this context, various studies conducted on adult populations pointed to a statistically significant correlation between social anxiety and depression (Faravelli et al., 2000; Pini et al., 1997; Wilson, \& Rapee, 2005), and a statistically significant correlation between social anxiety and social fear and social avoidance (Bjornsson et al., 2011; Zubeidat et al., 2007). Moreover, it was found that social anxiety disorder is positively linked to suicidal intentions among those with the disorder (Bjornsson et al., 2011). It was also found that the problems most overlapping with social anxiety are other anxieties, social fear and social avoidance of social situations (Faravelli et al., 2000; Magee et al., 1996).

A test was conducted on the third hypothesis in connection with the differences between specific social anxiety and generalized social anxiety in various demographic variables. The findings of this study indicated that there is a statistically significant difference between the two groups only in the age variable where the average age among student teachers with generalized social anxiety was found to be higher than the mean age among student teachers with specific social anxiety. The scientific literature contains a few studies which attempted to distinguish between categories of social anxiety on the basis of demographic variables. Kessler et al., 1994, argued that specific and generalized social anxiety are not clearly distinguishable, whereas Rapee, \& Heimberg, 1997, argue in theoretical cognitive-behavioural models that the essential nature of these two categories of specific social anxiety is similar. These researchers believe that these two forms of specific social anxiety are more similar than different, which supports the findings of this study. However, these are general arguments and this indicates that there is a need for future studies in order to differentiate between these two categories of social anxiety. In any event, most researchers (Heimberg et al., 1993; Hofmann et al., 1999; Ngata et al., 2015; Olivares et al., 2004) who described this topic used adult populations and noted that the demographic variables do not differentiate between the two forms of social anxiety in a statistically significant manner, a conclusion which corresponds with most of the findings of the third hypothesis because of the lack of statistically significant differences between specific and generalized social anxiety in the demographic variables gender, work, marital status, study speciality, academic year, study framework, income level and religious-ethnic background.

The study's findings relating to the fourth hypothesis indicated that there is a statistically significant difference between the two categories of social anxiety in the social anxiety, social fear and social avoidance aspects only of all the social-emotional and educational aspects measured. This finding emphasizes the finding of Rapee, \& Heimberg, 1997, which notes that the essential nature of specific and generalized social anxiety is more similar than different. This study maintains that there are no statistically significant differences between these two categories in terms of depression, motivation for learning, self-esteem and perceived social and family support, while student teachers with generalized social anxiety suffer from more levels of social anxiety, social fear and social avoidance than student teachers with specific social anxiety. As has been observed, the aspects linked to interaction and social performance situations are those which distinguish between student teachers with specific social anxiety and generalized social anxiety. These findings are similar to those of various researchers (Alden, \& Mellings, 2004; Ballesteros, \& Conde, 1999; Evans, Walukevich, \& Britton, 2016; Gelernter Stein, Tancer, \& Uhde 1992; Heimberg et al., 1993; Mannuzza et al., 1995; Yap et al., 2016) which revealed that people with generalized social anxiety report higher levels of anxiety in social interaction situations, and greater social fear and social avoidance of social situations that people with specific social anxiety. These findings could be the result of a lack of accuracy in the definition of the generalized type of social anxiety and the failure of DSM-5 to identify the basic characteristics, as noted in the introduction. Therefore, the findings of the study linked to the fourth hypothesis in this study are similar to the findings of the above-mentioned studies, which partly substantiate this hypothesis.

The findings of the study relating to the fifth hypothesis indicated that there is a statistically significant correlation between levels of depression and levels of social anxiety (specific and generalized), a statistically significant correlation between levels of motivation for learning and social anxiety, while there are no statistically significant correlations between levels of social anxiety and levels of self-esteem and between social anxiety and levels of perceived social and family support. These findings are partly similar to various study findings which reported statistically significant correlations between social anxiety and other anxieties (Evans et al., 2016; Faravelli et al, 2000; Magee et al, 1996) and depression (Faravelli et al, 2000; Wilson, \& Rapee, 2005; Pini et al, 1997; Koyuncu et al., 2015). In addition, previous findings reported that there is a statistically significant correlation between motivation for learning and levels of social anxiety among student teachers (Aggarwal, 2004; Elliot, \& McGregor, 2001; Thompson, \& Perry, 2005; Tseng, \& Tsay, 2010).

In conclusion, the regression analysis indicates differences in explaining the variance of specific social anxiety and generalized social anxiety among student teachers from Palestinian Arab minority in Israel. In fact, the findings indicate 
that student teachers suffer from social anxiety as well as other difficulties (political, economic, social, cultural and educational) such as to acquire basic academic skills, which is reflected in difficulties in academic writing and in learning to take exams. In many institutions of higher education there are no plans for academic assistance and counseling for Arab students. Some institutions have such programs, with encouraging results, but their scope is limited and often dependent on private donors. This situation is one of the main reasons for the phenomenon of "dragging the studies": only $12 \%$ of the Arab students finish their bachelor's degree in the appropriate time allotted to them (compared with 53\% of the Jews). The level of specific social anxiety of Palestinian Arab minority in Israel can be explained on the basis of their perceived level of social and family support and on the basis of their age, while the level of generalized social anxiety of the student teachers can be explained on the basis of depression and on the basis of their age. In this context the scientific literature indicates the importance of variables such as social support, depression and age in social anxiety as noted above. Nevertheless, future studies will attempt to conduct in-depth investigations of the explanation for social anxiety and its subtypes, specific and generalized, in order to acquire a deeper understanding of this phenomenon among the student teachers who are destined to become the teachers of tomorrow.

\section{Acknowledgements}

This study was conducted on recommendation of the Inter-Academic Research Committee at the Mofet Institute and supported by the Induction department at the Ministry of Education in Israel.

\section{References}

Abu-Asbeh, K. (2009). Arab Education in Israel: Between the Discourse of Struggling Identity and Low Achievement. Adalah's Newsletter, 63, 1-3.

Abu-Saad, I. (2006). Introduction: A Historical Context of Palestinian Education. The American Behavioral Scientist, 49(8), 1035-1051. https://doi.org/10.1177/0002764205284717

Agbaria, A., Mustafa, M., \& Jabreen, Y. (2015). 'In your face' democracy: education for belonging and its challenges in Israel. British Educational Research Journal, 41(1), 143-175. https://doi.org/10.1002/berj.3133

Aggarwal, J. C. (2004). Essentials of educational psychology. New Delhi: Vikas, Publishing House.

Alden, L. E., \& Mellings, T. M. (2004). Generalized social phobia and social judgments: The salience of self and partner information. Bahaviour Research and Therapy, 18, 297-316. https://doi.org/10.1007/BF02357507

Amara, M., Duneitz-Schmidt, S., \& Mari, P. (2016). The Arabic language in academia in Israel: historical absence, challenges in the present, prospects for the future. Jerusalem: Hochon Lear.

American Psychiatric Association. (2013). Diagnostic and statistical manual of mental disorders (5th ed.). Washington, DC: Author. https://doi.org/10.1176/appi.books.9780890425596

Amies, P. L., Gelder, M. G., \& Shaw, P. M. (1983). Social phobia: A comparative clinical study. British Journal of Psychiatry, 142, 174-179. https://doi.org/10.1192/bjp.142.2.174

Arar, K., \& Ibrahim, F. (2016). Education for national identity: Arab school principals and teacher dilemmas and coping strategies. Journal of Education Policy, 31(6), 681-693. https://doi.org/10.1080/02680939.2016.1182647

Ballesteros, M. C., \& Conde, V. J. (1999). Trastorno por ansiedad social de inicio en la infancia y la adolescencia. In J. G, Bobes, M. P., González, P. A., Sáiz \& G. Bousoño (Eds.), Abordaje actual del trastomo por ansiedad social (pp. 35-62). Barcelona: Masson.

Beck, A. T., Ward, C. H., Mendelson, M., Mock, J., \& Erbaugh, J. (1961). An inventory for measuring depression. Archives of General Psychiatry, 4, 561-571. https://doi.org/10.1001/archpsyc.1961.01710120031004

Beesdo-Baum, K., Knappe, S., Fehm, L., Hofler, M., Lieb, R., Hofmann, S. G., \& Wittchen, H. U. (2012). The natural course of social anxiety disorder among adolescents and young adults. Acta Psychiatrica Scandinavica, 126, 411-425. https://doi.org/10.1111/j.1600-0447.2012.01886.x

Bjornsson, A. S., Bidwell, L. C., Brosse, A. L., Carey, G., Hauser, M., Seghete, K. L. M., \& Craighead, W. E. (2011). Cognitive-Behavioral group therapy versus group psychotherapy for social anxiety disorder among college students: a randomized controlled trial. Depression and Anxiety, 28, 1034-1042. https://doi.org/10.1002/da.20877

Carlson, C., Uppal, S., \& Cprosser, E. (2000). Ethnic differences in processes contributing to the self-esteem of early adolescent girls. The Journal of Early Adolescence, 20, 44-67. https://doi.org/10.1177/0272431600020001003

CBS, Central Bureau of Statistics, Statistical Abstract of Israel, 2018

Chavira, D. A., Stein, M. B., Bailey, K., \& Stein, M. T. (2004). Child anxiety in primary care: prevalent but untreated. Depression and Anxiety, 20(4), 64-155. https://doi.org/10.1002/da.20039

Davidson, J. R. T., Hughes, D. C., George, L. K., \& Blazer, D. G. (1993). The boundary of social phobia: exploring the 
threshold. Archives of General Psychiatry, 51, 975-983. https://doi.org/10.1001/archpsyc.1994.03950120047008

Dryman, M., \& Heimberg, R. (2015). Examining the Relationships Among Social Anxiety, Fears of Evaluation, and Interpretation Bias. Cognitive Therapy \& Research, 39, 646-657. https://doi.org/10.1007/s10608-015-9694-4

Elliot, A. J., \& McGregor, H. A. (2001). A $2 \times 2$ achievement goal framework. Journal of Personality and Social Psychology, 80, 501-519. https://doi.org/10.1037/0022-3514.80.3.501

Essau, C. A., Conradt, J., \& Petermann, F. (2000). Frequency, comorbidity, and psychosocial impairment of anxiety disorders in adolescents. Journal of Anxiety Disorders, 14, 263-279. https://doi.org/10.1016/S0887-6185(99)00039-0

Evans, T. C., Walukevich, K. A., \& Britton, J. C. (2016). Vigilance-avoidance and disengagement are differentially associated with fear and avoidant behaviors in social anxiety. Journal of Affective Disorders, 199, 124-131. https://doi.org/10.1016/j.jad.2016.04.003

Faravelli, C., Zucchi, T., Viviani, B., Salmoria, R., Perone, A., Scarpato, A, .. Abrardi, L. (2000). Epidemiology of social phobia: A clinical approach. European Psychiatry, 15, 17-24. https://doi.org/10.1016/S0924-9338(00)00215-7

Fitts, W. H. (1965). Manual of Tennessee Self-Concept Scale. Nashville, TN: Mental Health Department.

Furmark, T., Tillfors, M., Stattin, H., Ekselius, L., \& Fredrikson, M. (2000). Social phobia subtypes in the general population revealed by cluster analyses. Psychological Medicine, 30, 1335-1344. https://doi.org/10.1017/S0033291799002615

Galbraith, T., Heimber, R., G., Wang, F. R., \& Blanco, C. (2013). Comorbidity of social anxiety disorder and antisocial personality disorder in the National Epidemiological Survey on Alcohol and Related Conditions (NESARC). Journal of Anxiety Disorders, 28, 57-66. https://doi.org/10.1016/j.janxdis.2013.11.009

Gelemter, C. S., Stein. M. B., Tancer, M. E., \& Uhde, T. W. (1992). An examination of syndromal validity and diagnostic subtypes in social phobia and panic disorder. Journal of Clinical Psychiatry, 53, $23-27$.

Gharrah, R. (2016). Arab Society in Israel-Population, Society and Economy. Press: The Van Leer Jerusalem Institute.

Heimberg, R. G., Holt, C. S., Schneier, F. R., Spitzer, R. L., \& Liebowitz, M. R. (1993). The issue of subtypes in the diagnosis of social phobia. Journal of Anxiety Disorders, 7, 249-269. https://doi.org/10.1016/0887-6185(93)90006-7

Hofmann, S. G., \& Roth, W. T. (1996). Issues related to social anxiety among controls in social phobia research. Behavior Therapy, 27, 79-91. https://doi.org/10.1016/S0005-7894(96)80037-2

Hofmann, S. G., Albano, A. M., Heimberg, R. G., Tracey, S., Chorpita, B. F., \& Barlow, D. H. (1999). Subtypes of social phobia in adolescents. Depression and Anxiety, 9, 15-18. https://doi.org/10.1002/(SICI)1520-6394(1999)9:1<15::AID-DA2>3.0.CO;2-6

Hyunjin, K., \& YoonJung, C. (2014). Pre-service teachers' motivation, sense of teaching efficacy, and expectation of reality shock. Asia-Pacific Journal of Teacher Education, 42, 67-81. https://doi.org/10.1080/1359866X.2013.855999

Jianzhong, X. (2014). Regulation of motivation: predicting students' homework motivation management at the secondary school level. Research Papers in Education, 29, 457-478. https://doi.org/10.1080/02671522.2013.775324

Jimenez, L., Sáiz, P. A., Bascarán, M. T., \& Iglesias, C. (1999). Epidemiología del trastorno por ansiedad social. In J. Bobes, M. P. González, P. A. Sáiz \& M. Bousoño (Eds.), Abordaje actual del trastorno por ansiedad social (pp. 3-26). Barcelona: Masson.

Kessler, R., McGonagle, K. A., Zhao, S., Nelson, C. B., Hughes, M., Eshleman, S., ... Kendler, K. S. (1994). Lifetime and 12-month prevalence of DSM-III psychiatric disorders in the United States: Results from the National Comorbidity Survey. Archives of General Psychiatry, 51, 8-19. https://doi.org/10.1001/archpsyc.1994.03950010008002

Koyuncu, A., Ertekin, E., Deveci, E., Ertekin, B. A., Yüksel, Ç., Çelebi, F., ... Tükel, R. (2015). Age of onset in social anxiety disorder: Relation to clinical variables and major depression comorbidity. Annals of Clinical Psychiatry (American Academy of Clinical Psychiatrists (AACP)), 27, 84-89.

Kupper, N., \& Denollet, J. (2012). Social anxiety in the general population: Introducing abbreviated versions of SIAS and SPS. Journal of Affective Disorders, 136, 90-98. https://doi.org/10.1016/j.jad.2011.08.014

La Greca, A. M., Ingles, C. J., Lai, B. S., \& Marzo, J. C. (2015). Social Anxiety Scale for Adolescents: Factorial Invariance across Gender and Age in Hispanic American Adolescents. Assessment, 22, $224-232$. https://doi.org/10.1177/1073191114540749 
Leary, M. R., \& Kowalski, R. M. (1995). Social anxiety. Nueva York: Guilford Press.

Lewinsohn, P. M., Zinbarg, R., Seeley, J. R., Lewinsohn, M., \& Sack, W. H. (1997). Lifetime comorbidity among anxiety disorders and between anxiety disorders and other mental disorders in adolescents. Journal of Anxiety Disorders, 11, 377-394. https://doi.org/10.1016/S0887-6185(97)00017-0

Liebowitz, M. R. (1987). Social phobia. Modern Problems in Pharmacopsychiatry, 22, 141-173. https://doi.org/10.1159/000414022

Lim, M. H., Rodebaugh, T. L., Gleeson, J. F., \& Zyphur, M. J. (2016). Loneliness over time: The crucial role of social anxiety. Journal of Abnormal Psychology, 125, 620-630. https://doi.org/10.1037/abn0000162

Magee, W. J., Eaton, W. W., Wittchen, H. U., McGonagle, K. A., \& Kessler, R. C. (1996). Agoraphobia, simple phobia, and social phobia in the National Comorbidity Survey. Archives of General Psychiatry, 53, 159-168. https://doi.org/10.1001/archpsyc.1996.01830020077009

Mannuzza, S., Schneier, F. R., Champan, T. F., Liebowitz, M. R., Klein, D. F., \& Fyer, A. J. (1995). Generalized social phobia: Reliability and validity. Archives of General Psychiatry, 52, 230-237. https://doi.org/10.1001/archpsyc.1995.03950150062011

Moss, H. B. (2013). The impact of alcohol on society: a brief overview. Social Work in Public Health 28, 175-177. https://doi.org/10.1080/19371918.2013.758987

Muldoon, O. T., \& Trew, K. (2000). Social group membership and perception of the self in northern Irish children. International Journal of Behavioral Development, 24, 330-337. https://doi.org/10.1080/01650250050118312

Myers, J. K., Weissman, M. M., \& Tischler, G. L. (1984). Six-month prevalence of psychiatric disorders in three communities. Archives of General Psychiatry, 41, 959-967. https://doi.org/10.1001/archpsyc.1984.01790210041006

Nagata, T., Suzuki, F., \& Teo, A. R. (2015). Generalized social anxiety disorder: A still-neglected anxiety disorder 3 decades since Liebowitz's review. Psychiatry \& Clinical Neurosciences, 69, 724-740. https://doi.org/10.1111/pcn.12327

Obeid, N., Buchholz, A., Boerner, K. E., Henderson, K. A., \& Norris, M. (2013). Self-Esteem and Social Anxiety in an Adolescent Female Eating Disorder Population: Age and Diagnostic Effects. Eating Disorders, 21, 140-153. https://doi.org/10.1080/10640266.2013.761088

Olivares, J., Piqueras, J. A., \& Sánchez-García, R. (2004). "Escala para la Detección de la Ansiedad Social (EDAS)": estructura factorial y fiabilidad en una muestra de adolescentes entre 14 y 18 años. Psicología Conductual, 12, 251-268.

Pacek, L. R., Storr, C. L., Mojtabi, R., Green, K. M., La Flair, L., N., Alvanzo, A. A. H., ... Crum, R., M. (2013). Comorbid alcohol dependence and anxiety disorders: A national survey. Journal of Dual Diagnosis, 9, 271-280. https://doi.org/10.1080/15504263.2013.835164

Patel, A., Knapp, M., Henderson, J., \& Baldwin, D. (2002). The economic consequences of social phobia. Journal of Affective Disorders, 68, 221-233. https://doi.org/10.1016/S0165-0327(00)00323-2

Peleg, O. (2005). The relation between differentiation and social anxiety: What can be learned from students and their parents? The American Journal of Family Therapy, 33, 167-183. https://doi.org/10.1080/01926180590921403

Pini, S., Cassano, G. B., Simonini, E., Savino, M., Russo, A., \& Montgomery, S. A. (1997). Prevalence of anxiety disorders comorbidity in bipolar depression, unipolar depression and dysthymia. Journal of Affective Disorders, 42, 169-180. https://doi.org/10.1016/S0165-0327(96)01405-X

Pintrich, P., Smith, D., Garcia, T., \& McKeachie, W. (1991). A manual for the use of the motivated strategies for learning questionnaire (MSLQ). National Center for Research to Improve Post-secondary Teaching and Learning: Ann Arbor, Michigan.

Rabe-Jablonska, J., Dietrich-Muszalska, A., \& Gmitrowicz, A. (2004). The prevalence of social phobia in a representative group of adolescents from Lodz. Archives of Psychiatry and Psychotherapy, 6, 15-22.

Ranta, K., Junttila, N., Laakkonen, E., Uhmavaara, A., La Greca, A. M., \& Niemi, P. M. (2012). Social Anxiety Scale for Adolescents (SAS-A): Measuring Social Anxiety among Finnish Adolescents. Child Psychiatry \& Human Development, 43, 574-591. https://doi.org/10.1007/s10578-012-0285-2

Rapee, R. M., \& Heimberg, R. G. (1997). A cognitive-behavioral model of anxiety in social phobia. Behavior Research and Therapy, 35, 741-756. https://doi.org/10.1016/S0005-7967(97)00022-3

Rosenberg, M. (1965). Society and the adolescent self-image. Princeton, NJ: Princeton University Press. https://doi.org/10.1515/9781400876136 
Schneier, F. R., Foose, T. E., Hasin, D. S., Heimberg, R. G., Liu, S. M., Grant, B. F., \& Blanco, C. (2010). Social anxiety disorder and alcohol use disorder comorbidity in the National Epidemiologic Survey on Alcohol and Related Conditions. Psychological Medicine, 40, 977-988. https://doi.org/10.1017/S0033291709991231

Segal, S., \& Ezer, H. (2009). Pressure on teacher training and its implications for the student teacher training. Research report, Research authority: Levinsky College.

Shilli, M. (2014). The importance of the Hebrew language for the integration and advancement of the Arab population in the employment market. One of the main recommendations of the Caesarea Forum for the Advancement of Arab Men and Arab Women in Israel, 18, 1-9.

Shohami, A. (2014). "Linguistic and Social Policy in Israel," Smadar Dunietz-Schmidt and Ofra Inbar-Luria (editors). Issues in Language Teaching in Israel (pp. 17-42). Tel Aviv: The Mofet and Klil Institute.

Stein, M. B., \& Deutsch, R. (2003). In search of social phobia subtypes: Similarity of feared social situations. Depression and Anxiety, 17, 94-97. https://doi.org/10.1002/da.10093

Stein, M. B., Torgrud, L. J., \& Walker, J. R. (2000). Social Phobia Symptoms, Subtypes, and Severity. Archives of General Psychiatry, 57, 1046-1052. https://doi.org/10.1001/archpsyc.57.11.1046

Stevens, S., Cludius, B., Banti, T., Hermann, C., \& Gerlach, A. (2014). Influence of alcohol on social anxiety: An investigation of attentional, physiological and behavioral effects. Biological Psychology, 96, 126-133. https://doi.org/10.1016/j.biopsycho.2013.12.004

Taylor, E. R., Wooten, R., Babcock, B., \& Hill, F. (2002). A metaphorical story to raise relational esteem in Mexican American families of low socioeconomic status. Family Journal, 10, 27-33. https://doi.org/10.1177/1066480702101005

Thompson, T., \& Perry, Z. (2005). Is the poor performance of self-worth protective students linked with social comparison goals? Educational Psychology, 25, 471-490. https://doi.org/10.1080/01443410500045558

Tseng, S. C., \& Tsai, C. C. (2010) .Taiwan college students' self-efficacy and motivation of learning in online peer assessment environments. Internet and Higher Education, 3, 234-250. https://doi.org/10.1016/j.iheduc.2010.01.001

Turner, S. M., \& Beidel, D. C. (1989). Social phobia: Clinical syndrome, diagnosis, and comorbidity. Clinical Psychology Review, 9, 3-18. https://doi.org/10.1016/0272-7358(89)90043-3

Weiller, E., Bisserbé, J. C., Boyer, P., Lepine, J. P., \& Lecrubier, Y. (1996). Social phobia in general health care: an unrecognized undertreated disabling disorder. British Journal of Psychiatry, 168, 169-174. https://doi.org/10.1192/bjp.168.2.169

Wilson, J. K., \& Rapee, M. R. (2005).The interpretation of negative social events in social phobia with versus without comorbid mood disorder. Journal of Anxiety Disorders, 19, 245-274. https://doi.org/10.1016/j.janxdis.2004.03.003

Wittchen, H. U., Stein, M. B., \& Kessler, R. C. (1999). Social fears and social phobia in a community sample of adolescents and young adults: prevalence, risk factors and comorbidity. Psychological Medicine, 29, 309-323. https://doi.org/10.1017/S0033291798008174

Yap, K., Gibbs, A., L., Francis, A. J. P., \& Schuster, S. E. (2016). Testing the Bivalent Fear of Evaluation Model of Social Anxiety: The Relationship between Fear of Positive Evaluation, Social Anxiety, and Perfectionism. Cognitive Behaviour Therapy, 45, 136-149. https://doi.org/10.1080/16506073.2015.1125941

Zimet, G. D., Dahlem, N. W., Zimet, S. F., \& Farley, G. K. (1988). The Multidimensional Scale of perceived social support. Journal of Personality Assessment, 52, 30-41. https://doi.org/10.1207/s15327752jpa5201_2

Zubeidat, I., Salinas, J. M., Sierra, J. C., \& Fernández-Parra, A. (2007). Psychometric properties of the Social Interaction Anxiety Scale and separation criterion between Spanish youths with and without subtypes of social anxiety. Journal of Anxiety Disorders, 21, 603-624. https://doi.org/10.1016/j.janxdis.2006.09.010

\section{Copyrights}

Copyright for this article is retained by the author(s), with first publication rights granted to the journal.

This is an open-access article distributed under the terms and conditions of the Creative Commons Attribution license which permits unrestricted use, distribution, and reproduction in any medium, provided the original work is properly cited. 